\title{
Sustainable Development Goals and Human Rights Edited by Markus Kaltenborn, Markus Krajewski, and Heike Kuhn
}

\author{
Switzerland AG: Springer Nature. Interdisciplinary Studies in Human \\ Rights, Volume 5; 2020
}

\section{Victoria M. Breting-Garcia ${ }^{1}$}

Published online: 14 April 2021

(C) The Author(s), under exclusive licence to Springer Nature B.V. 2021

In July 2019, as the ink dried on the final draft of the preface of the Springer Nature publication Sustainable Development Goals and Human Rights, the volume's authors and editors could not have imagined how the world would change in the months following its publication in early 2020. By April of 2020, nearly 3.9 billion people - more than half of the global population - were living in lockdown as the spread of a coronavirus (SARS-CoV-2) pandemic ravaged communities and economies. The aftershocks of the pandemic still reverberate through the global economy, with critical impacts on global supply chains, global healthcare, community development, education, housing, labor, and the environment. Similarly, heightened concerns for human dignity, autonomy, and freedom of association during times of emergency have raised concerns for human rights law and the correlative dangers of authoritarian leadership during times of crisis.

The search for common ground for global cooperation across a broad spectrum of identified goals and outcomes for sustainable development and well-being has never been more urgent. It is the subject of the Springer Nature open access publication, Sustainable Development Goals and Human Rights (2020). Editors Markus Kaltenborn, Markus Krajewski, and Heike Kuhn curate a forum for studying the complex "intellectual merger" of the "parallel universes" of sustainable development and international human rights law. In twelve chapters, multiple viewpoints are presented to illuminate the striking similarities and common perspectives that inspire developmental policy and international human rights protection. Each chapter serves as a multi-relational resource for further study in each topic area, with hyperlinked footnotes and references for easy access to a wealth of secondary resource materials.

As with the original eight U.N. Millennium Development Goals, the eradication of poverty and hunger are primary goals that continue to challenge global relief

Victoria M. Breting-Garcia

vickimarga2@aol.com

1 Victoria M. Breting-Garcia, National Coalition of Independent Scholars, Houston, TX, USA 
organizations worldwide. In October of 2020 The World Bank warned that, as a result of the pandemic, as many as 150 million people worldwide, including urban dwellers, would be reduced to living in extreme poverty by 2021. In his essay, "How Can a Human Rights-Based Approach Contribute to Poverty Reduction? The Relevance of Human Rights to Sustainable Development Goal One," author Hans-Otto Sano considers the variable impacts of neoliberalism, deregulation and privatization on the development of measures that emphasize local self-determination and improved access to technology and services.

Volume editor Markus Kaltenborn and Delanyo Dovlo offer complementary perspectives on the urgent need for universal health coverage and the challenges of establishing viable programs for social protection in their essays - "The Human Rights Framework for Establishing Social Protection Floors and Achieving Universal Health Coverage," and "People and Their Health Systems: The Right to Universal Health Coverage and the SDGs in Africa."

The 2030 SDGs Goal 5 re-emphasizes the ongoing concerns of women. As families transitioned to stay-at-home work and study during quarantine, the COVID-19 outbreak brought to sharp focus the "triple burden" of women's unequal participation in the workplace, in the family, and in the community. These issues are addressed in the essay, "Freedom from Violence, Full Access to Resources, Equal Participation, and Empowerment: The Relevance of CEDAW for the Implementation of the SDGs," by Beate Rudolf, and authors Josephine A. Odera and Judy Mulusa with their essay, "SDGs, Gender Equality and Women's Empowerment: What Prospects for Delivery?"

Christoph Scherrer's analysis of "Superfluous Workers: Why SDG 8 Will Remain Elusive" gives a sober appraisal of global labor markets and the decent work deficit. In February of 2021, the U.S. Bureau of Labor Statistics reported that 14.8 million people lost employment as businesses closed in response to the pandemic. Unemployment, income inequality, and informal employment continue to have disastrous real-time impacts on labor markets worldwide.

Editor Heike Kuhn approaches human rights from the lens of SDG Goal 10 - the reduction of inequalities both within and among countries in her essay, "Reducing Inequality Within and Among Countries: Realizing SDG 10 - A Development Perspective." This article analyzes the reasons for the remarkable agreement expressed by the 193 U.N. member states, as derived from studies directed by the World Bank linking inequality to other intransigent socioeconomic, environmental, and political drivers.

Seven of the 2030 SDGs make direct reference to the issues of clean water and sanitation (Goal 6), affordable and clean energy (Goal 7), sustainable cities and communities (Goal 11), responsible consumption and production (Goal 12), climate action (Goal 13), life below water (Goal 14), and life on land (Goal 15). Running through these themes is an emerging global consensus that climate change is a primary driver for finding sustainable solutions addressing the full 2030 development platform. These relationships are the subject of Alan Boyle's essay, "Climate Change, Sustainable Development, and Human Rights," and Imme Scholz's essay, "Reflecting on the Right to Development from the Perspective of Global Environmental Change and the 2030 Agenda for Sustainable Development."

The final SDG Goals 16 and 17 address the need for resilient governance institutions and partnerships to promote the development of peaceful and effective societies. These goals are explored in the final chapters of this collection - "Scrutinizing Sustainable 
Development? The Coercive Sting in SDG 16" by Liora Lazarus, "The Role of Public and Private Actors and Means in Implementing the SDGs: Reclaiming the Public Policy Space for Sustainable Development and Human Rights" by Jens Martens, and "Towards a Division of Labour for Sustainable Development: Extraterritorial Human Rights Obligations" by Wouter Vandenhole.

This full collection of essays provides a timely synthesis of research and inquiry introducing the reader to the critical issues that the U.N. Agenda 2030 intends to address on a global scale. The Springer Nature editorial board is to be commended for the exceptional quality of its ongoing support of the U.N. 2030 development agenda and the international human rights platform, and for its effort to guarantee open access serving the widest possible audience.

Publisher's Note Springer Nature remains neutral with regard to jurisdictional claims in published maps and institutional affiliations. 